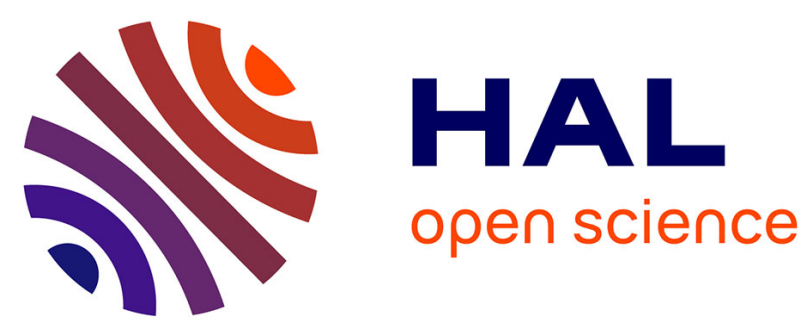

\title{
Phase formation sequence in the Ti/InP system during thin film solid-state reactions
}

Elodie Ghegin, Philippe Rodriguez, J.L. Labar, M. Menyhard, S. Favier, Isabellle Sagnes, Fabrice Nemouchi

\section{To cite this version:}

Elodie Ghegin, Philippe Rodriguez, J.L. Labar, M. Menyhard, S. Favier, et al.. Phase formation sequence in the $\mathrm{Ti} / \mathrm{InP}$ system during thin film solid-state reactions. Journal of Applied Physics, 2017, 121, pp.245311. 10.1063/1.4990427 . cea-01559841

\section{HAL Id: cea-01559841 https://hal-cea.archives-ouvertes.fr/cea-01559841}

Submitted on 11 Jul 2017

HAL is a multi-disciplinary open access archive for the deposit and dissemination of scientific research documents, whether they are published or not. The documents may come from teaching and research institutions in France or abroad, or from public or private research centers.
L'archive ouverte pluridisciplinaire HAL, est destinée au dépôt et à la diffusion de documents scientifiques de niveau recherche, publiés ou non, émanant des établissements d'enseignement et de recherche français ou étrangers, des laboratoires publics ou privés. 


\section{Phase formation sequence in the $\mathrm{Ti} / \mathrm{InP}$ system during thin film solid-state reactions}

E. Ghegin, Ph. Rodriguez, J. L. Lábár, M. Menyhárd, S. Favier, I. Sagnes, and F. Nemouchi

Citation: Journal of Applied Physics 121, 245311 (2017); doi: 10.1063/1.4990427

View online: http://dx.doi.org/10.1063/1.4990427

View Table of Contents: http://aip.scitation.org/toc/jap/121/24

Published by the American Institute of Physics

\section{AIP | Journal of A1P Applied Physics}

Save your money for your research.

It's now FREE to publish with us no page, color or publication charges apply.
Publish your research in the

Joumal of Applied Physics

to claim your place in applied

physics history. 


\title{
Phase formation sequence in the $\mathrm{Ti} / \mathrm{InP}$ system during thin film solid-state reactions
}

\author{
E. Ghegin, ${ }^{1,2,3, a)}$ Ph. Rodriguez, ${ }^{2}$ J. L. Lábár, ${ }^{4}$ M. Menyhárd, ${ }^{4}$ S. Favier,,${ }^{1,2}$ I. Sagnes, ${ }^{5}$ \\ and F. Nemouchi ${ }^{2}$ \\ ${ }^{1}$ STMicroelectronics, 850 rue Jean Monnet, BP 16, 38926 Crolles, France \\ ${ }^{2}$ Univ. Grenoble Alpes, F-38000 Grenoble, France and CEA, LETI, MINATEC Campus, F-38054 Grenoble, \\ France \\ ${ }^{3}$ CNRS-C2N, Route de Nozay, 91460 Marcoussis, France \\ ${ }^{4}$ MTA EK MFA, Konkoly Thege M. u. 29-33, H-1121 Budapest, Hungary \\ ${ }^{5}$ Centre de Nanosciences et de Nanotechnologies, CNRS, Univ. Paris-Sud, Université Paris-Saclay, \\ C2N-Marcoussis, 91460 Marcoussis, France
}

(Received 14 March 2017; accepted 14 June 2017; published online 30 June 2017)

\begin{abstract}
The metallurgical properties of the $\mathrm{Ti} / \mathrm{InP}$ system meet a great interest for its use as a contact in the scope of various applications such as the Si Photonics. The investigations conducted on this system highlight the initiation of a reaction between the $\mathrm{Ti}$ and the $\mathrm{InP}$ substrate during the deposition process conducted at $100{ }^{\circ} \mathrm{C}$. The simultaneous formation of two binary phases, namely, $\operatorname{Ti}_{2} \mathrm{In}_{5}$ and $\mathrm{TiP}$, is attributed to the compositional gradient induced in the InP by the wet surface preparation and enhanced by the subsequent in situ $\mathrm{Ar}^{+}$preclean. Once formed, the TiP layer acts as a diffusion barrier inhibiting further reaction up to $450{ }^{\circ} \mathrm{C}$ in spite of the presence of an important $\mathrm{Ti}$ reservoir. At higher temperature, however, i.e., from $550{ }^{\circ} \mathrm{C}$, the reaction is enabled either by the enhancement of the species diffusion through the TiP layer or by its agglomeration. This reaction gives rise to the total consumption of the $\mathrm{Ti}_{2} \mathrm{In}_{5}$ and Ti while the TiP and In phases are promoted. Published by AIP Publishing. [http://dx.doi.org/10.1063/1.4990427]
\end{abstract}

\section{INTRODUCTION}

Allowing data rates beyond what electronic components can offer, photonics have been identified as one promising paradigm. However, while silicon is of huge interest for the making of most components, its indirect band gap prevents it from being an efficient light emitter. For addressing this issue, III-V semiconductor compounds have been introduced as potential candidates. Among them, n-InP substrates and the corresponding metal interfaces have been extensively studied for improving the performances of such devices. Among others, $\mathrm{Ti}$ is one of the most widely used metals in the classical $\mathrm{Ti} / \mathrm{Pt} / \mathrm{Au}$ contacts, where it provides the primary role of improved metallization adhesion. ${ }^{1}$ In these stacks, the Ti being directly in contact with the semiconductor mainly rules the electrical properties of the integrated contacts. Therefore, in the scope of forming noble material-free contacts, the study of alloyed Ti-based metallizations is of particular interest.

In order to make such contacts, the main process flow consists of a surface preparation (wet and/or plasma treatments), one or several metal layer depositions and a heat treatment. These processes aim to control the intermetallic compound(s) formation, thereby modifying the contact resistivity. Each phase arising from the solid state reactions offers various electrical properties (resistivity, work function, Schottky barrier height, interface and gap defects...) and thermokinetic properties (dopant and/or element distribution, growth kinetics, thermal stability, texture...). As a

\footnotetext{
${ }^{\text {a) }}$ Author to whom correspondence should be addressed: elodie.ghegin@st.com
}

consequence, it is necessary to identify the phase formation sequence along with the range of existence of each compound.

Most studies present in the literature report the initiation of a reaction between the $\mathrm{Ti}$ and the $\mathrm{InP}$ during the deposition process, without any critical minimum coverage. ${ }^{2-6}$ Some In release is featured and associated with the formation of intermixed Ti-P layer; ${ }^{2-6}$ only one study does not report the formation of intermixed compound during the deposition process but identifies the first signs of reaction at $325^{\circ} \mathrm{C} .{ }^{7} \mathrm{At}$ higher temperatures, however, i.e., from $300^{\circ} \mathrm{C}$ to $350{ }^{\circ} \mathrm{C}$ depending on the studies, all authors found out that the intermixed layer is converted into stable crystalline binary Ti-P intermetallic compounds. The composition of the latter is not ascertained but might comprise some TiP and/or $\mathrm{Ti}_{4} \mathrm{P}_{3}$. However, even if both phases coexist, the TiP appears to be predominant. The formation of these compounds is associated with some In out diffusion and with an incomplete consumption of the Ti. As a consequence, the authors conclude that the TiP phase acts as a diffusion barrier thereby inhibiting further reaction between the $\mathrm{Ti}$ and the $\mathrm{InP}$ even at temperatures as high as $600^{\circ} \mathrm{C}$.

In this paper, we investigate the phase sequence obtained on the $\mathrm{Ti}(20 \mathrm{~nm}$ or $50 \mathrm{~nm}) / \mathrm{InP}$ systems under rapid thermal processes (RTP) and identify the mechanisms responsible for the appearance of the various observed phases.

\section{EXPERIMENTAL PROCEDURE}

The metallurgical studies were carried out on semiinsulating (001) InP substrates on top of which a $300 \mathrm{~nm} \mathrm{InP}$ 
epitaxial layer was grown. The substrate cleaning procedure includes a 30 s wet etching in dilute $\mathrm{HCl}: \mathrm{H}_{2} \mathrm{O}(1: 2)$ solution followed by a direct $\mathrm{Ar}^{+}$plasma etching (RF1: $130 \mathrm{~W}$; RF2: $310 \mathrm{~W}$ ) prior to the metal deposition process. The 20 and $50 \mathrm{~nm}$-thick titanium films were deposited by physical vapor deposition (magnetron sputtering in DC mode) at $100{ }^{\circ} \mathrm{C}$ and capped by $7 \mathrm{~nm}$ thick TiN films deposited at the same temperature. This kind of encapsulation protects the Ti film from any atmospheric contamination and/or oxidation, which could alter the reactions taking place at the $\mathrm{Ti} / \mathrm{InP}$ interface. The $\mathrm{Ar}^{+}$preclean and the deposition of the metal layers were performed in the same equipment, thereby avoiding air breaks. Then, RTP processes were conducted under $\mathrm{NH}_{2}$ ambient for $60 \mathrm{~s}$ at temperatures ranging from $250^{\circ} \mathrm{C}$ to $550{ }^{\circ} \mathrm{C}$.

Both, the as deposited and the reacted films were characterized by Auger Electron Spectroscopy (AES) and cross sectional Transmission Electron Microscopy (TEM). Samples dedicated to the TEM analysis were prepared by focused $\mathrm{Ga}^{+}$-ion beam (FIB) and $\mathrm{Ar}^{+}$-ion milling. All samples were also characterized thanks to X-Ray Diffraction (XRD) detexturation. Detexturation consists in acquiring $\theta / 2 \theta$ diffractograms at several $\chi$ angles (8 scans from 0 to $70^{\circ}$ by steps of $10^{\circ}$ - see Appendix A for the description of the various angles of a four-circle diffractometer). The sum of all these diffractograms gives access to a higher number of diffraction lines, as well as higher peak intensity. This kind of XRD is well optimized for thin films because they are often textured, and their diffracting volume is small, especially, in the early stages of their formation.

\section{RESULTS}

\section{A. As deposited systems}

The Ti being known as a very reactive metal on InP, the composition of the Ti/InP system right after deposition was determined thanks to the XRD detexturation. For doing so, several Ti thicknesses ranging from 20 to $50 \mathrm{~nm}$ were probed as displayed in Fig. 1.

In accordance with most results reported in literature, the XRD patterns highlight the initiation of the reaction between

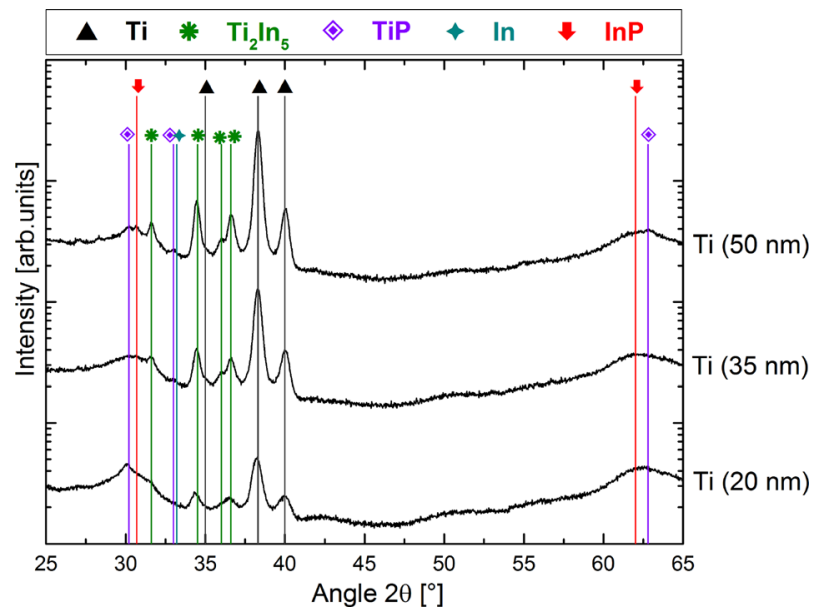

FIG. 1. XRD detexturation patterns of the as deposited TiN (7 nm)/Ti (20, 35 , and $50 \mathrm{~nm}) / \mathrm{InP}$ samples.
$\mathrm{Ti}$ and InP during the deposition process. ${ }^{2-6}$ This reaction appears to be incomplete as several peaks corresponding to the $\mathrm{Ti}$ are still observed, even when only $20 \mathrm{~nm}$ of metal were initially deposited. The XRD patterns highlight the formation of at least two binary and crystalline phases, the hexagonal $\mathrm{TiP}$, and the tetragonal $\mathrm{Ti}_{2} \mathrm{In}_{5}$. While the formation of the first phase is largely reported in literature, the second has not been observed yet. It is important to note that some In might also be present in these systems as one peak might be attributed to this phase $\left(2 \theta=33^{\circ}\right)$. However, this assumption could hardly be affirmed, thanks solely to the XRD, as this peak could also be attributed to TiP. Therefore, in order to identify more precisely the nature and the repartition of the various phases, additional TEM combined with AES characterizations were conducted on the TiN $(7 \mathrm{~nm}) / \mathrm{Ti}(20 \mathrm{~nm}) / \mathrm{InP}$ and TiN $(7 \mathrm{~nm}) /$ $\mathrm{Ti}(50 \mathrm{~nm}) / \mathrm{InP}$ systems (Figs. 2 and 3).

The low magnification TEM images highlight the homogeneity and the continuity of the layers present on the InP [Fig. 2(a)]. Increasing the magnification reveals the presence of two different layers underneath the $\mathrm{Ti}$ whose grains are about $40 \mathrm{~nm}$ wide [Fig. 2(b)]. Although both layers' thicknesses are not perfectly homogeneous within each system, they are independent of the initially deposited Ti thickness:

- The thickness of layer-1 ranges from $3 \mathrm{~nm}$ to $8 \mathrm{~nm}$ within each sample;

- The thickness of layer-2 ranges from $7 \mathrm{~nm}$ to $15 \mathrm{~nm}$ within each sample.

Selected Area Electron Diffraction (SAED) pattern and its indexation are shown in Fig. 2(c). When a diffraction spot can be attributed to more than one phase, the most probable is given in first. Even if SAED technique does not probe the same interreticular planes than XRD, it exhibits the presence of the same phases $\mathrm{Ti}$, TiN, TiP, and $\mathrm{Ti}_{2} \mathrm{In}_{5}$. Additionally, the TEM cross section features an important contrast in terms of composition between the two layers. Taking into account the atomic masses of $\mathrm{Ti}\left(47.87 \mathrm{~g} \mathrm{~mol}^{-1}\right)$, In $\left(114.82 \mathrm{~g} \mathrm{~mol}^{-1}\right)$, and $\mathrm{P}\left(30.97 \mathrm{~g} \mathrm{~mol}^{-1}\right)$, and the results obtained on the XRD characterization, one must reasonably assume that the observed stack is composed of TiN/Ti/ $\mathrm{Ti}_{2} \mathrm{In}_{5} / \mathrm{TiP} / \mathrm{InP}$. Additional AES characterizations were conducted in order to confirm or deny this conclusion. Because they are very similar, Fig. 3 displays solely the results corresponding to the system $\mathrm{TiN}(7 \mathrm{~nm}) / \mathrm{Ti}(20 \mathrm{~nm}) / \mathrm{InP}$.

As supported by the AES depth profile, the two layers present very different compositions. The AES depth profiles are smeared due to the roughness of the corresponding layers. While the layer in contact with the Ti (layer-2) is composed of a mixture of $\mathrm{Ti}$ and $\mathrm{In}$, the layer in contact with the InP (layer-1) consists of Ti and P. As a consequence, the various characterizations indicate the fact that the Ti reacts with the InP during the deposition process conducted at $100{ }^{\circ} \mathrm{C}$ to form the layered structure: $\mathrm{TiN}(7 \mathrm{~nm}) / \mathrm{Ti}^{2} / \mathrm{Ti}_{2} \operatorname{In}_{5}(7$ to $15 \mathrm{~nm}$ )/TiP (3 to $8 \mathrm{~nm}) / \mathrm{InP}$.

\section{B. Annealed samples}

In order to determine the evolution of the structure identified after deposition, additional characterizations were 

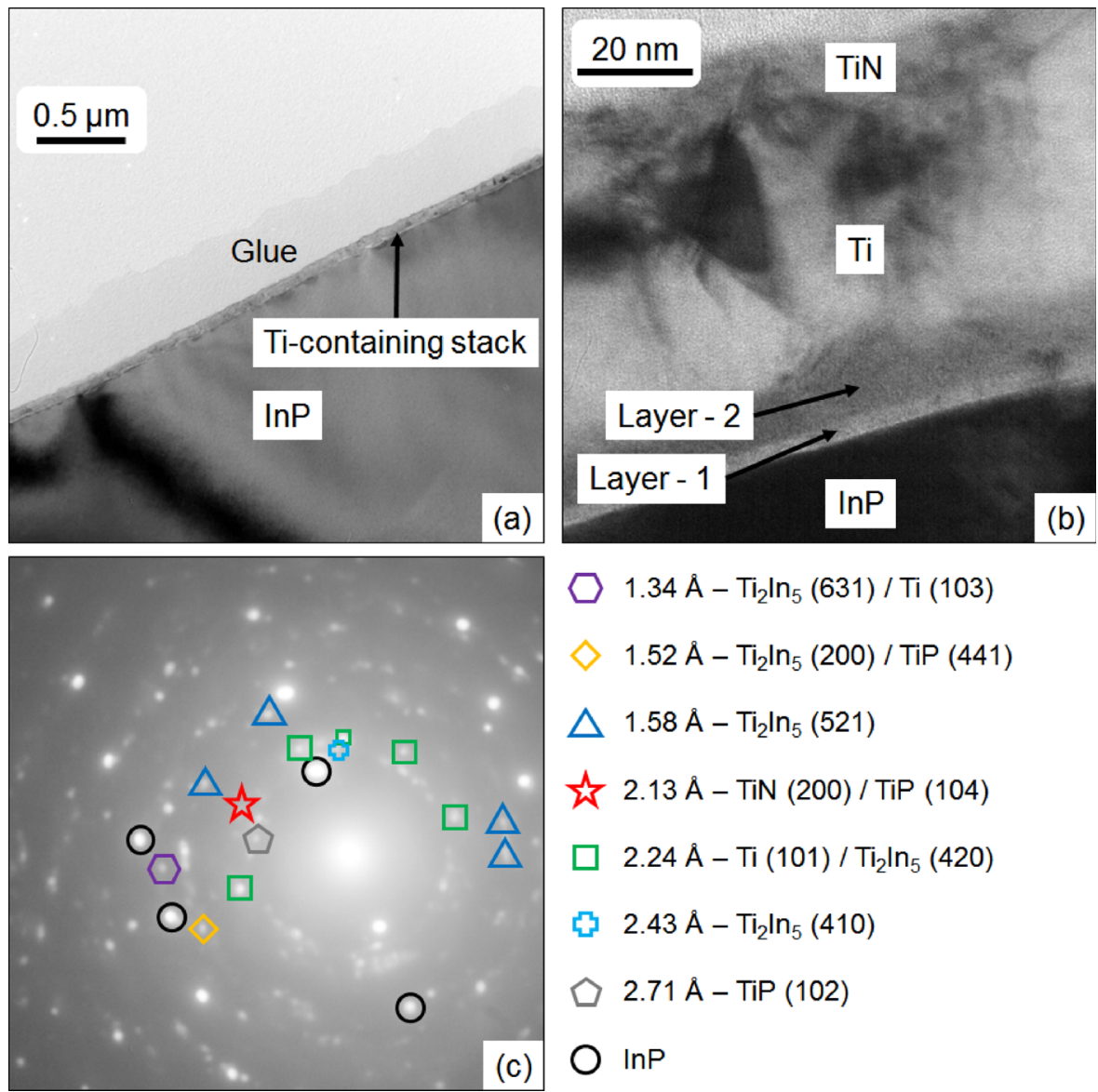

$1.34 \AA-\mathrm{Ti}_{2} \mathrm{In}_{5}(631) / \mathrm{Ti}(103)$

$1.52 \AA-\mathrm{Ti}_{2} \ln _{5}(200) / \mathrm{TiP}(441)$

$1.58 \AA-\mathrm{Ti}_{2} \ln _{5}(521)$

$2.13 \AA-\operatorname{TiN}(200) / \mathrm{TiP}(104)$

$2.24 \AA-T i(101) / T_{2} \ln _{5}(420)$

$2.43 \AA-\mathrm{Ti}_{2} \ln _{5}(410)$

$2.71 \AA-\operatorname{TiP}(102)$

(c) $\bigcirc \ln P$
FIG. 2. Bright field TEM cross section of (a) the $\mathrm{TiN}(7 \mathrm{~nm}) / \mathrm{Ti}(20 \mathrm{~nm}) / \mathrm{InP}$ as deposited sample in low magnification, (b) the $\mathrm{TiN}(7 \mathrm{~nm}) / \mathrm{Ti}(50 \mathrm{~nm}) / \mathrm{InP}$ as deposited sample in high magnification and (c) the corresponding SAED pattern highlighting the presence of four different layers in the system. conducted on samples annealed thanks to RTP processes at temperatures ranging from 250 to $550{ }^{\circ} \mathrm{C}$. The XRD detexturation patterns corresponding to these samples are presented in Figs. 4 and 5, for initial Ti thicknesses of 20 and $50 \mathrm{~nm}$, respectively.

When only $20 \mathrm{~nm}$ of Ti are initially deposited, the diffractograms highlight the coexistence of the three phases already observed, i.e., $\mathrm{Ti}, \mathrm{Ti}_{2} \mathrm{In}_{5}$, and $\mathrm{TiP}$, at temperatures up to $450{ }^{\circ} \mathrm{C}$ (Fig. 4). Furthermore, the intensity of every diffraction peak is constant throughout the annealing temperatures, and thus, do not indicate the evolution of the phases

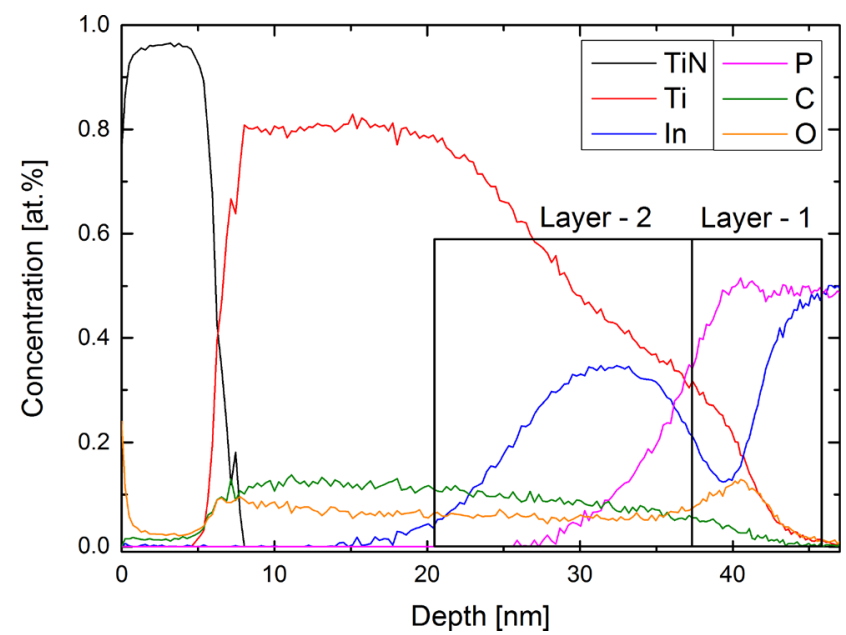

FIG. 3. AES depth profile corresponding to the as deposited TiN $(7 \mathrm{~nm}) / \mathrm{Ti}$ $(20 \mathrm{~nm}) / \mathrm{InP}$ system. from 250 to $450{ }^{\circ} \mathrm{C}$. However, increase in the initial Ti thickness to $50 \mathrm{~nm}$ leads to a modification of the behavior of the diffraction peak (Fig. 5). Indeed, peaks corresponding to the $\mathrm{Ti}_{2} \mathrm{In}_{5}$ and the TiP are not present in all the samples, and most importantly, seem to disappear at some temperature. For example, one of the most intense TiP peak $\left(2 \theta=30.3^{\circ}\right)$ is absent at $250^{\circ} \mathrm{C}$, while the XRD analyses conducted after deposition and at higher temperatures indicate the presence of this compound in the corresponding systems. Similarly, all the peaks corresponding to the $\mathrm{Ti}_{2} \mathrm{In}_{5}$ at angles ranging

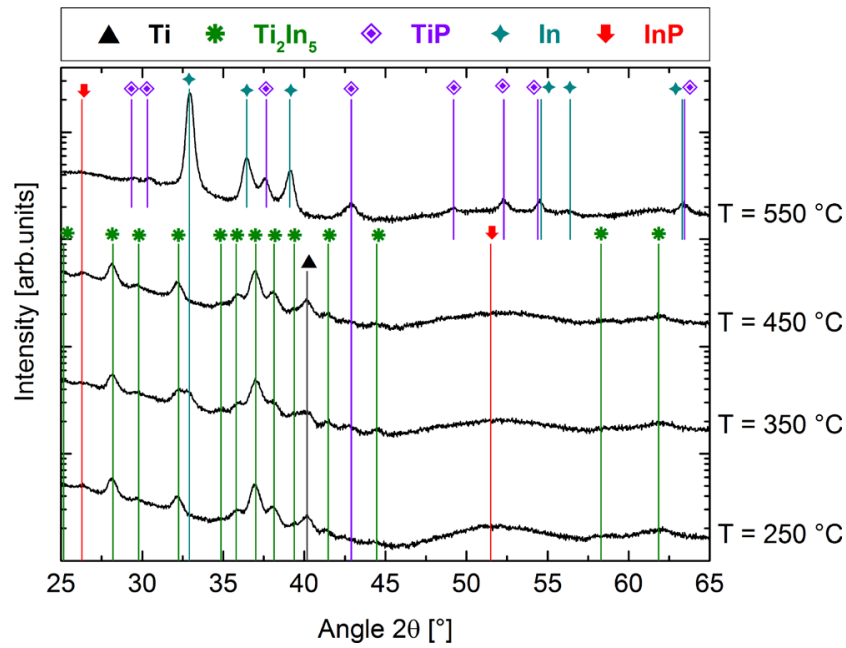

FIG. 4. XRD detexturation patterns of the TiN $(7 \mathrm{~nm}) / \mathrm{Ti}(20 \mathrm{~nm}) / \mathrm{InP}$ samples annealed at $250,350,450$, and $550^{\circ} \mathrm{C}$ for $60 \mathrm{~s}$ (RTP). A $2^{\circ}$ offset on the incident beam was applied in order to minimize the InP substrate contribution. 


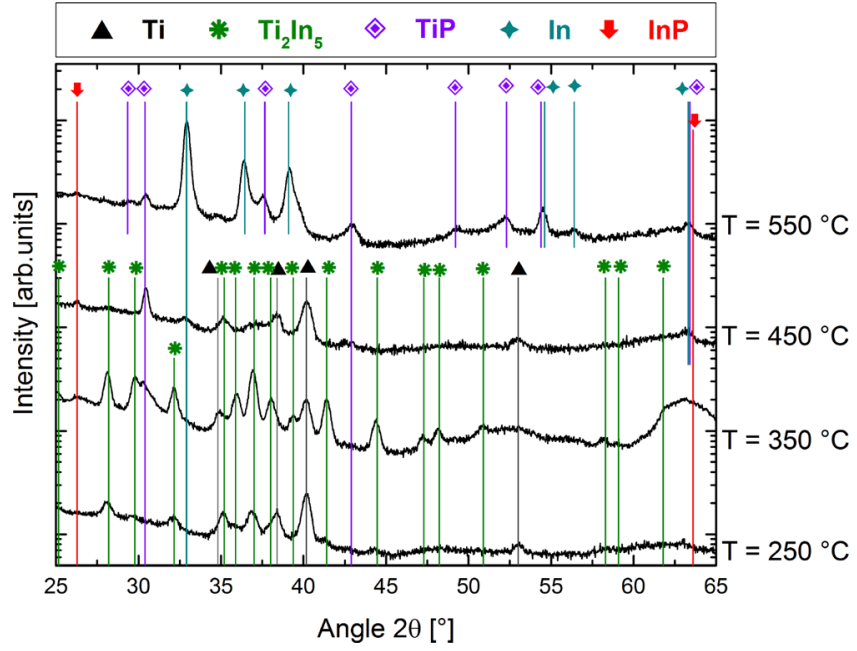

FIG. 5. XRD detexturation patterns of the TiN $(7 \mathrm{~nm}) / \mathrm{Ti}(50 \mathrm{~nm}) / \mathrm{InP}$ samples annealed at $250,350,450$, and $550{ }^{\circ} \mathrm{C}$ for $60 \mathrm{~s}$ (RTP). A $2^{\circ}$ offset on the incident beam was applied in order to minimize the InP substrate contribution.

from $45^{\circ}$ to $65^{\circ}$ are absent in the patterns acquired after annealing treatments conducted at $250^{\circ} \mathrm{C}$ and $450^{\circ} \mathrm{C}$ while they are present at $350^{\circ} \mathrm{C}$. Therefore, the extinction of some peaks seems to be uncorrelated with the actual composition of the systems and may be attributed to the combined effect of the measurement geometry and the crystallographic texture of these compounds. Indeed, even though diffractograms were acquired at several $\chi$ angles to give rise to the summed patterns presented in Figs. 4 and 5, no rotation was performed around the $\phi$ angle in this configuration (A schematic representation of the different angles of a four-circle diffractometer is shown in Fig. 11 in Appendix A). Therefore, some orientations might be extinct depending on the initial positioning of the sample/wafer with respect to the X-Ray beam. In order to confirm or deny this hypothesis, TEM and AES characterizations were conducted on the system presenting an initial Ti thickness of $50 \mathrm{~nm}$ annealed at $450^{\circ} \mathrm{C}$ (Fig. 6).

The TEM cross section along with the AES depth profile feature the presence of four distinct layers, which are very similar to the ones observed after deposition in terms of morphology and thicknesses. The layer 1 in contact with the InP substrate and composed of $\mathrm{Ti}$ and $\mathrm{P}$ is still about $3-8 \mathrm{~nm}$ thick, while the thickness of the layer 2 composed of Ti and In, still ranges from 7 to $15 \mathrm{~nm}$. Note that the roughness present in this system results in transitions that are less net on the corresponding AES depth profile. As a consequence, the layer's thicknesses are somewhat overestimated in this profile compared to the ones actually measured in the corresponding TEM cross sections and presented here. However, although the roughness seems to be increased by this thermal treatment, the various compounds are still arranged in the layered structure already observed after deposition: TiN $(7 \mathrm{~nm}) / \mathrm{Ti} /$ $\mathrm{Ti}_{2} \mathrm{In}_{5}$ ( 7 to $15 \mathrm{~nm}$ )/TiP (3 to $8 \mathrm{~nm}$ )/InP. As a consequence, the modification of the diffractograms from $250{ }^{\circ} \mathrm{C}$ to $450^{\circ} \mathrm{C}$ is most likely linked to a texture of the observed compounds rather than to an actual modification of the systems' composition. For initially deposited Ti thickness ranging from 20 to $50 \mathrm{~nm}$, the TiP and the $\mathrm{Ti}_{2} \mathrm{In}_{5}$ are formed during the

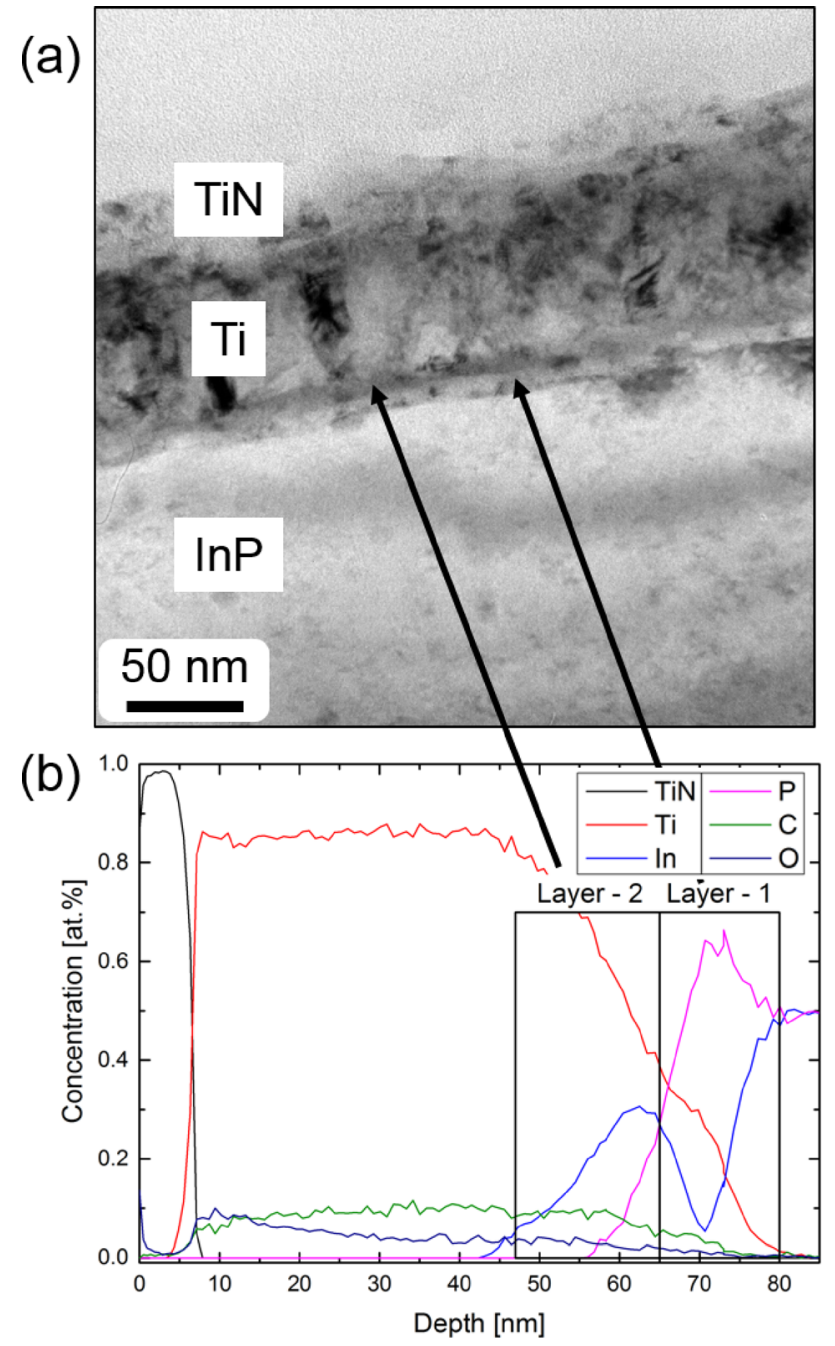

FIG. 6. (a) TEM cross section of the TiN $(7 \mathrm{~nm}) / \mathrm{Ti}(50 \mathrm{~nm}) / \mathrm{InP}$ system annealed at $450{ }^{\circ} \mathrm{C}$ and (b) corresponding AES depth profile.

deposition process and are stable in terms of composition and thicknesses at temperatures as high as $450^{\circ} \mathrm{C}$.

However, contrary to the observations made in this range of temperature, a drastic change of composition is brought by an increase in the temperature to $550^{\circ} \mathrm{C}$. At this point, a complete redistribution of the species present in the sample leads to the total consumption of the $\mathrm{Ti}$ and $\mathrm{Ti}_{2} \mathrm{In}_{5}$. The latter are replaced by the already observed TiP phase. The stoichiometry conservation leads to some In release as confirmed by the corresponding XRD patterns.

\section{DISCUSSION}

In Sec. III, thanks to the combined results emanating from XRD, TEM, and AES, the composition of Ti (20 to $50 \mathrm{~nm}$ )/InP systems was determined from deposition temperature to $550^{\circ} \mathrm{C}$. It was found that a layered structure composed of $\mathrm{Ti}, \mathrm{Ti}_{2} \mathrm{In}_{5}$ and $\mathrm{TiP}$ is formed during the deposition process conducted at $100^{\circ} \mathrm{C}$ and is stable up to $450{ }^{\circ} \mathrm{C}$. However, further increasing the temperature up to $550^{\circ} \mathrm{C}$ leads to a consumption of the $\mathrm{Ti}$ and the $\mathrm{Ti}_{2} \mathrm{In}_{5}$ to promote the TiP and In.

The initial appearance of Ti-In phases along with Ti-P phases has not been reported yet in this kind of systems. 
Because it might modify their electrical properties or their thermal stability, the phenomena responsible for the appearance of the $\mathrm{Ti}_{2} \mathrm{In}_{5}$ are worth identifying. Similar discrepancies were observed on other systems and attributed to the different data treatment used by the various groups. ${ }^{8,9}$ In our case, the identification of the phases could hardly be questioned as a multitude of diffracting peaks confirms the indexation of each phase in Figs. 4 and 5. However, as detailed in the experimental procedure, all samples were dipped into a concentrated $\mathrm{HCl}$ solution and subjected to an $\mathrm{Ar}^{+}$preclean before the metallization deposition in order to remove the native oxides and contaminants from the InP surface. Studies concerning the effect of these surface preparations showed that both treatments modify the InP surface's stoichiometry. ${ }^{10-14}$

\section{A. Impact of the InP surface preparation}

In order to further understand the individual effect of the wet and the dry preparation on our systems, two additional samples were prepared. The first one was only dipped in the $\mathrm{HCl}: \mathrm{H}_{2} \mathrm{O}=(1: 2)$ wet solution while the second one was additionally submitted to the $\mathrm{Ar}^{+}$plasma. In order to avoid Ti and InP intermixing, no Ti layer was deposited. However, the $7 \mathrm{~nm}$-thick TiN layer was deposited on the InP immediately after the surface preparations in order to prevent any parasitic oxidation or contamination of its surface. The TEM images along with the corresponding AES depth profiles are presented in Fig. 7.

The TEM image corresponding to the sample that was subjected to the Ar preclean [Fig. 7(a)] features an important roughness with a discontinuous TiN film, which morphology is determined by the individual TiN grains. An amorphous layer of about $10 \mathrm{~nm}$ is also identified, similarly to the results reported in a previous study. ${ }^{13}$ Because of the important roughness, the corresponding AES depth profile is highly smeared and the signals emanating from the InP, the amorphous layer, and the TiN top layer are not clearly distinct. Nonetheless, a compositional gradient can be observed in the profile. It, therefore, appears that this kind of plasma leads to a phosphorus depletion of the InP surface consistently with what was previously reported in the literature. ${ }^{10-13}$ The region situated below this In-rich area appears to be P-rich over a few nanometers. One can notice an $\mathrm{O}$ signal emanating from the top region of the sample. Because of the important roughness, it would not be possible to assert if it comes from the original InP surface or an oxidation occurring
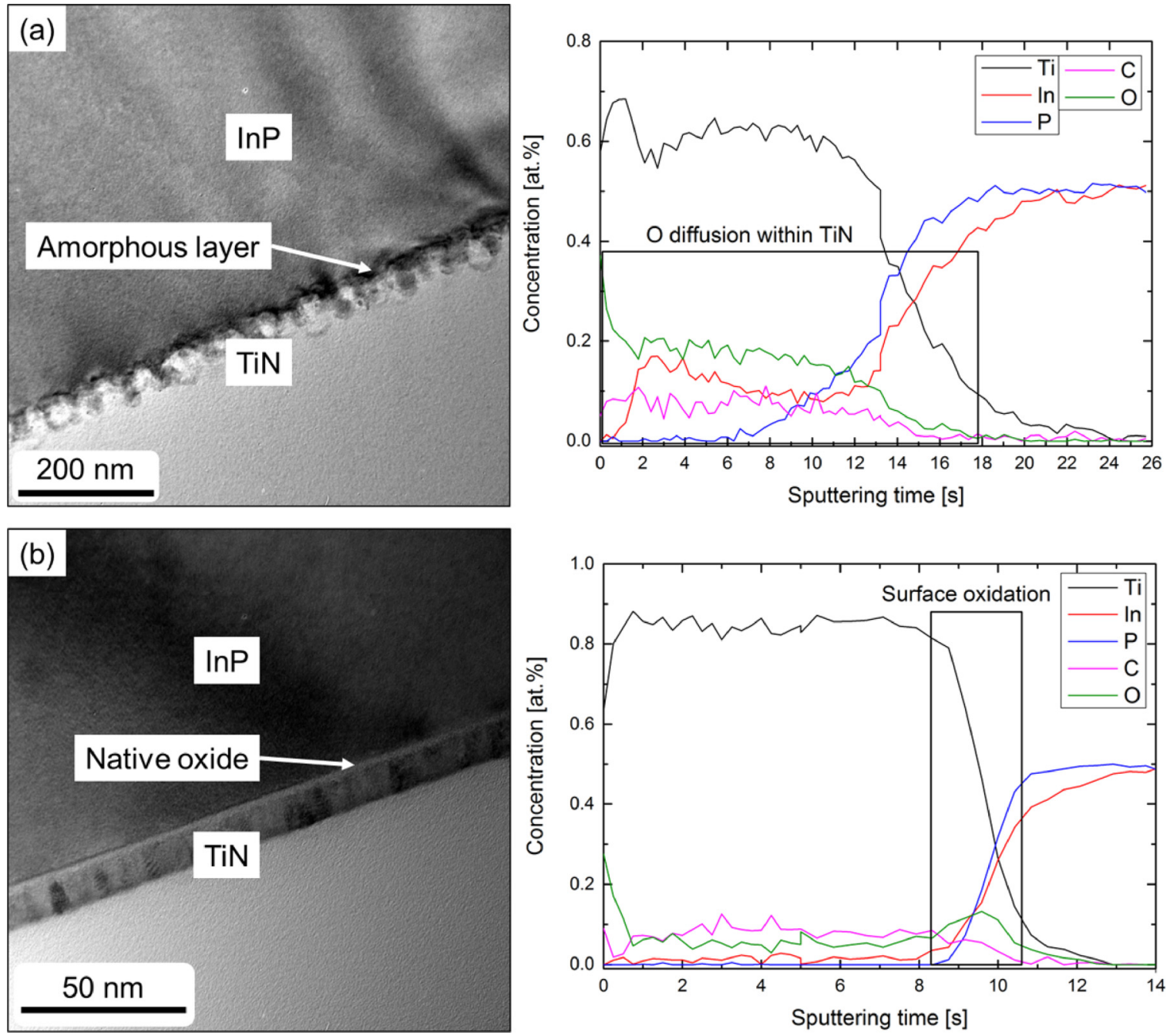

FIG. 7. Bright field TEM images and corresponding AES depth profiles of TiN ( $7 \mathrm{~nm}) / \mathrm{InP}$ samples $(\mathrm{a})$ after an $\mathrm{HCl}$ : $\mathrm{H}_{2} \mathrm{O}=1: 2$ wet surface preparation combined with an in situ $\mathrm{Ar}^{+}$plasma treatment and (b) after an $\mathrm{HCl}: \mathrm{H}_{2} \mathrm{O}=1: 2$ wet surface preparation. 
afterwards because of the TiN layer discontinuity. However, studies conducted in our group showed the efficiency of this kind of InP surface preparation, and are, therefore, in favor of the second hypothesis. ${ }^{12}$ When no plasma treatment is conducted, the morphology of the layers drastically changes [Fig. 7(b)]. The TiN layer observed in this case is continuous and homogeneous, which results in a net AES depth profile. In the latter, the various layers can be clearly distinguished from one another. Particularly, the presence of an oxide layer on the InP surface comes as no surprise because of the absence of in situ surface preparation before the metal deposition. This native oxide, which is 2 to $3 \mathrm{~nm}$ thick can be seen in the corresponding TEM cross section. A compositional gradient similar to the one observed after the $\mathrm{Ar}^{+}$ plasma treatment is also observed within this native oxide. It, therefore, appears that the wet surface preparation conducted before the in situ preclean starts to deplete $\mathrm{P}$ from the InP surface. This assumption is in accordance with the findings of Cuypers et al. who showed that at high concentrations $([\mathrm{HCl}] \geq 2 \mathrm{M})$, the $\mathrm{HCl}$ molecule is not dissolved within the solution and anisotropically etches the InP surface. ${ }^{14}$ This etching process results in the formation of terraces, which are preferentially In-terminated. Therefore, the creation of a compositional gradient at the surface of the InP is first induced by concentrated $\mathrm{HCl}$ solutions and strongly emphasized by the in situ $\mathrm{Ar}^{+}$plasma treatments.

\section{B. Mechanisms involved in the phase formation sequence}

In accordance with literature, our results highlight the fact that both the concentrated $\mathrm{HCl}$ solution and the $\mathrm{Ar}^{+}$ plasma treatment create an amorphous layer, which presents a compositional gradient at the InP surface. The latter is, thus, In-rich at its top and P-rich at its bottom. During the subsequent Ti deposition, which is conducted by PVD at $100^{\circ} \mathrm{C}$, the atoms are deposited on this modified surface. Some atoms are directly in contact with the In-rich region while a non-negligible portion also reaches the P-rich InP area, either thanks to their kinetic energy and/or thanks to a short length diffusion process. The compositional gradient present in the InP, therefore, leads to the formation of two distinct layers, the $\mathrm{Ti}_{2} \mathrm{In}_{5}$ in the In-rich region and the TiP below. This situation is schematically represented in Fig. 8 .

In order to identify more precisely the involved mechanisms, one must additionally consider the results presented in literature. In most studies, no extensive details are given concerning the surface preparation, with the exception of Takeya et al. who dipped their InP substrates into HF solutions. ${ }^{3,4}$ It is, therefore, consistent to assume that the InP surfaces used in these studies have not been modified, and are thus, composed of 50 at. \% of In and 50 at. \% of P. As a consequence, it appears that when the InP surface's stoichiometry is not modified, the formation of Ti-P phases is favored at temperatures as low as $20^{\circ} \mathrm{C}$. This observation leads to two conclusions

(i) The gain in free energy $\left(\Delta \mathrm{G}_{\mathrm{v}}\right)$ associated with the formation of TiP in unmodified InP is so important that it compensates the increase of surface energy $(\Delta \sigma)$ linked to the nucleation of the phase at temperatures as low as $20^{\circ} \mathrm{C}$. Therefore, the formation of this compound is not limited by the nucleation on intact InP and is thermodynamically favourable on this kind of surface.

(ii) The overall gain in free energy $\left(\Delta \mathrm{G}_{\mathrm{n}}\right)$ associated with the formation of TiP when Ti and unmodified InP are brought in contact is more important than the one associated with the formation of $\mathrm{Ti}_{2} \mathrm{In}_{5}$. Note that $\Delta \mathrm{G}_{\mathrm{n}}$ takes into account the gain in free energy associated with the formation of the binary phase $\left(\Delta \mathrm{G}_{\mathrm{v}}\right)$ and the surface energy required for the forming of new interfaces $(\Delta \sigma)$.

On the other hand, when the InP surface is modified by the surface preparation and becomes In-rich, these considerations are no longer verified. The kinetic energy due to the PVD deposition brings Ti atoms close to/into the modified layer. In this case, even if the free energy gain would have been maximized by forming the TiP phase, the $\mathrm{Ti}_{2} \mathrm{In}_{5}$ phase is favored because of the available In excess. Just like TiP, the gain in free energy associated with the formation of $\mathrm{Ti}_{2} \mathrm{In}_{5}$ compensates the surface energy required for forming the nuclei at temperatures as low as $100^{\circ} \mathrm{C}$. The appearance of this phase is, therefore, not limited by the nucleation process. However, because the TiP phase is thermodynamically more stable in intact InP surfaces, the system tends to form this phase in the regions where the nominal InP stoichiometry is preserved, i.e., below the top few $\mathrm{InP}$ nanometers. The formation of Ti-P phases is even more favored in the present case as a P-rich region is present right below the In-rich layer. These mechanisms are in accordance with the

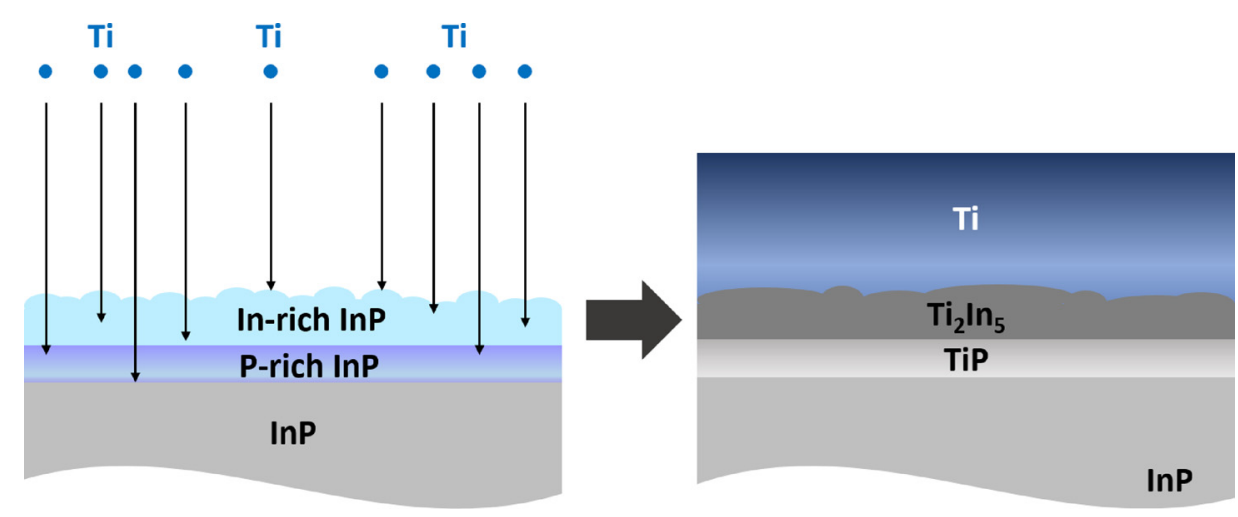

FIG. 8. Schematic representation of the formation of the $\mathrm{Ti}_{2} \mathrm{In}_{5}$ and $\mathrm{TiP}$ phase during the deposition process. 

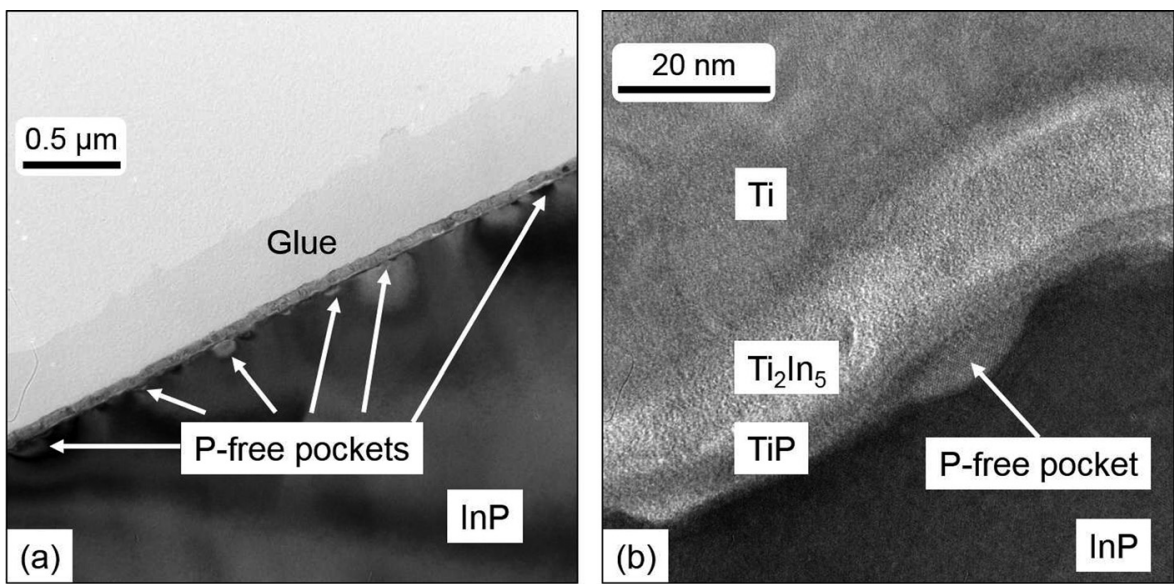

FIG. 9. TEM cross section of the as deposited $\mathrm{TiN}(7 \mathrm{~nm}) / \mathrm{Ti}(20 \mathrm{~nm}) / \mathrm{InP}$ system showing the presence of P-free pockets below the TiP layer. observed layered structure, where the P-rich phase lies below the In-rich one. Furthermore, the formation of the $\mathrm{Ti}_{2} \mathrm{In}_{5}$ and TiP must occur simultaneously. The $\mathrm{P}$ release associated with the appearance of the $\mathrm{Ti}_{2} \mathrm{In}_{5}$, therefore, helps the formation of the TiP; similarly, the In released during the formation of the TiP is at least partially consumed to form the $\mathrm{Ti}_{2} \mathrm{In}_{5}$. Once continuous TiP and $\mathrm{Ti}_{2} \mathrm{In}_{5}$ layers are formed, at least one of them acts as a diffusion barrier (bulk and/or grain boundary diffusion), therefore, inhibiting further reaction up to $450{ }^{\circ} \mathrm{C}$. It is important to note that even though both layers can inhibit the diffusion, based on literature, the TiP probably plays the most important role. Additionally, Pfree "pockets" are observed below the TiP layer as displayed in Fig. 9. One can reasonably assume that these pockets appear during the formation of the TiP layer. As mentioned above, when the $\mathrm{Ti}$ and the $\mathrm{InP}$ react together to form the TiP, some In must be released. A certain proportion of the In participates in the formation of the $\mathrm{Ti}_{2} \mathrm{In}_{5}$ provided that it not blocked by the TiP diffusion barrier. However, the proportion of In that is released underneath this TiP layer cannot diffuse through it or in the InP substrate, and is, therefore, constrained to stay in the TiP/InP interface. These pockets are, therefore, composed of pure In whose peaks are observed in the corresponding diffractograms.

As a consequence, it appears that the $\mathrm{Ti}_{2} \mathrm{In}_{5}$ and the TiP are most probably formed simultaneously during the deposition process by reaction between the $\mathrm{Ti}$ and the InP surface submitted by the two steps surface preparation. Once the TiP layer is thick enough to be continuous, the reaction is inhibited, and the system is stable up to $450{ }^{\circ} \mathrm{C}$. At higher temperatures, however, i.e., at $550{ }^{\circ} \mathrm{C}$, a drastic change of composition is observed as the system is only composed of TiP and In. Therefore, during this annealing process, the $\mathrm{Ti}_{2} \mathrm{In}_{5}$ is decomposed into $\mathrm{In}$, which strongly diffracts into additional Ti. This additional $\mathrm{Ti}$ along with the originally deposited one must meet the $\mathrm{P}$ contained in the substrate in order to enable the growth of the TiP.

Therefore, a path must be created during this annealing process in order to allow the various species to move and meet. At this point, several hypotheses can be formulated.

(A)

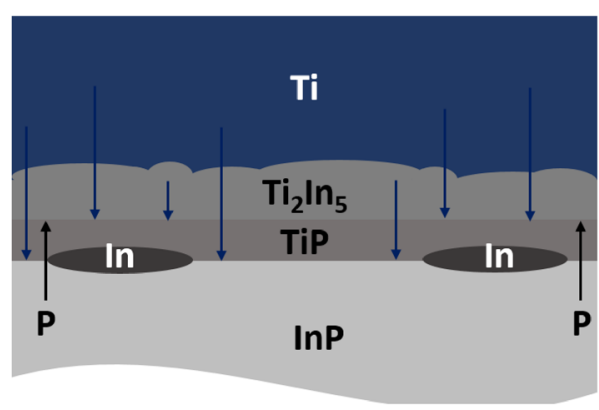

(B)

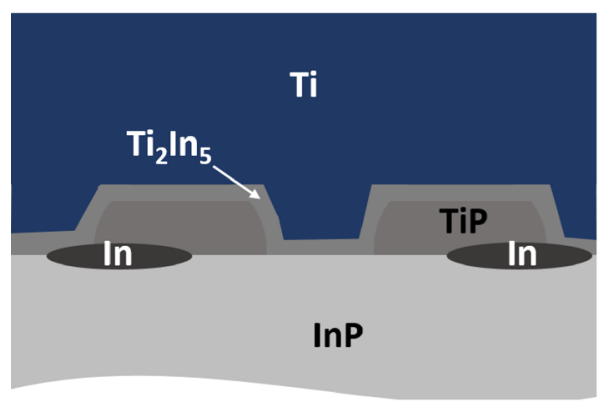

(B')

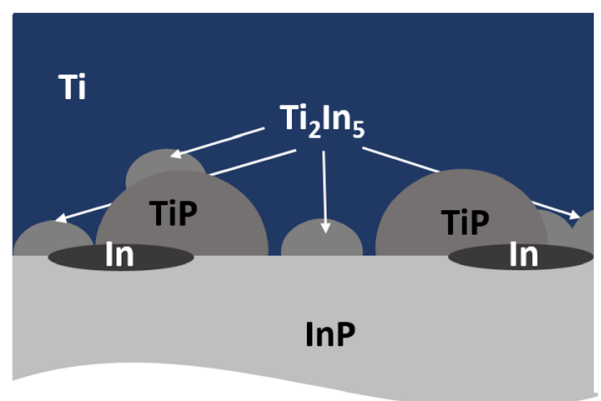

FIG. 10. Schematic representation of the three situations that could enable the species to interact during the annealing treatment conducted at $550^{\circ} \mathrm{C}$ with (A) the diffusion of the species through the TiP and $\mathrm{Ti}_{2} \mathrm{In}_{5}$ layers, (B) the agglomeration of the TiP layer and $\left(\mathrm{B}^{\prime}\right)$ the agglomeration of the TiP and $\mathrm{Ti}_{2} \mathrm{In}_{5}$ layers. Note that these diagrams represent the intermediate states occurring throughout the annealing process. 
(i) The increase in temperature might enhance the diffusion of the various elements, therefore, enabling them to diffuse fast enough through the TiP layer [Fig. 10(A)]. This diffusion can occur in the bulk phase, via interstitial and/or substitutional sites or thanks to the grain boundaries. Depending on the diffusion coefficients associated with the Ti and $\mathrm{P}$ in this phase, the growth of this phase can occur at the $\mathrm{Ti}_{2} \mathrm{In}_{5} / \mathrm{TiP}$ interface, therefore, limiting the length over which the $\mathrm{Ti}$ would have to diffuse and/or at the $\mathrm{TiP} / \mathrm{InP}$ interface, thereby limiting the length over which $\mathrm{P}$ would have to diffuse.

(ii) The second hypothesis that can be formulated lies in the assumption that the diffusion of the various species through the TiP layer is still too slow to enable any reaction. The layer(s) must, therefore, become discontinuous at $550^{\circ} \mathrm{C}$ in order to allow the $\mathrm{Ti}$ and $\mathrm{P}$ to interact. This process can be due to an agglomeration of the TiP layer only [Fig. 10(B)] or the agglomeration of both the TiP and $\mathrm{Ti}_{2} \mathrm{In}_{5}$ layers [Fig. 10(B')]. In both cases, once the $\mathrm{Ti}$ and the InP are in contact, the system tends to minimize its energy. As already mentioned, all the studies present in the literature report the formation of the TiP phase in intact InP surfaces, indicating the fact that this phase is the most stable in InP. As a consequence, because the few Inrich nanometers that were initially present on the InP have been consumed, the formation of the TiP phase is favored and associated with some In release to conserve the overall stoichiometry.

The second hypothesis appears to be the most likely, first, because the mechanisms related to the first one depend on the Ti thickness. The diffusion of the various species should indeed require much more time when $50 \mathrm{~nm}$ of Ti were deposited compared to the case were only $20 \mathrm{~nm}$ were initially present. Yet, the "Ti- $20 \mathrm{~nm}$ " and "Ti- $50 \mathrm{~nm}$ " seem to evolve similarly at $550^{\circ} \mathrm{C}$. As a consequence, the agglomeration of the layer(s) at this temperature is highly probable.

\section{CONCLUSION}

In conclusion, we demonstrated that the reaction between $\mathrm{Ti}$ and the underlying InP substrate is initiated during the deposition process conducted at $100{ }^{\circ} \mathrm{C}$. This reaction gives rise to the simultaneous formation of two binary phases, namely $\mathrm{Ti}_{2} \mathrm{In}_{5}$ and TiP. While the latter is largely reported in the literature, the first one had never been observed. We attribute the simultaneous formation of both phases to a compositional gradient induced in the InP by the wet surface preparation conducted in a concentrated $\mathrm{HCl}$ solution and enhanced by an in situ $\mathrm{Ar}^{+}$preclean. In accordance with literature, the TiP layers are found to act as a diffusion barrier inhibiting further reaction up to $450^{\circ} \mathrm{C}$ in spite of the presence of an important Ti reservoir. In this configuration, all observed phases, i.e., $\mathrm{Ti}_{2} \mathrm{In}_{5}, \mathrm{P}$, TiP, and $\mathrm{In}$, therefore, coexist at temperatures up to $450{ }^{\circ} \mathrm{C}$. Because the promotion of the TiP is thermodynamically more favorable, the $\mathrm{Ti}_{2} \mathrm{In}_{5}$ tends to be consumed in order to promote the TiP. However, this transition requires the appearance of a diffusion path within the TiP layer that is only be achieved at high temperature, i.e., at $550{ }^{\circ} \mathrm{C}$. The growth of this phase is accompanied by an In release and a total consumption of the $\mathrm{Ti}_{2} \mathrm{In}_{5}$ and Ti. Therefore, at $550^{\circ} \mathrm{C}$ the reaction is enabled either by the enhancement of the species diffusion through the TiP layer or by its agglomeration.

\section{ACKNOWLEDGMENTS}

This work was funded, thanks to the French National Research Agency (ANR), under the "Investissements d'avenir" program: IRT Nanoelec' ANR-10-AIRT-05.

\section{APPENDIX A: DESCRIPTION OF THE ANGLES OF A FOUR-CIRCLE DIFFRACTOMETER}

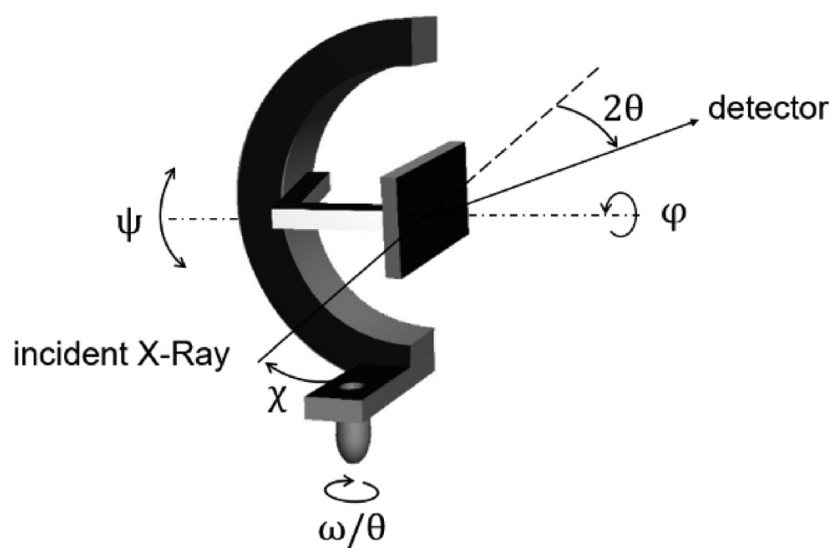

FIG. 11. Schematic representation of a variant of a four-circle diffractometer.

\section{APPENDIX B: INVENTORY OF DIFFRACTION PEAKS USED FOR THE INDEXATION OF XRD PATTERNS}

The following tables (Tables I-V) show the list of the Powder Diffraction Files (PDF) from the International Centre for Diffraction Data (ICDD) and the peaks used for the indexation of the XRD patterns shown in this study.

TABLE I. Indexed peaks of InP. InP-ICDD PDF 00-032-0452-Cubic $(\mathrm{F} \overline{4} 3 \mathrm{~m})$.

\begin{tabular}{lcc}
\hline \hline 2 theta $(\mathrm{Cu})$ & $(\mathrm{hkl})$ & Intensity \\
\hline 26.284 & $(111)$ & 100 \\
63.358 & $(400)$ & 10 \\
\hline \hline
\end{tabular}

TABLE II. Indexed peaks of In. In-ICDD PDF 00-005-0642-Tetragonal (I4/ $\mathrm{mmm})$.

\begin{tabular}{lcc}
\hline \hline 2 theta $(\mathrm{Cu})$ & $(\mathrm{hkl})$ & Intensity \\
\hline 32.965 & $(101)$ & 100 \\
36.328 & $(002)$ & 21 \\
39.170 & $(110)$ & 36 \\
54.477 & $(112)$ & 24 \\
56.593 & $(200)$ & 12 \\
63.204 & $(103)$ & 16 \\
\hline \hline
\end{tabular}


TABLE III. Indexed peaks of Ti. Ti-ICDD PDF 00-044-1294-Hexagonal $\left(\mathrm{P}_{3} / \mathrm{mmc}\right)$.

\begin{tabular}{lcc}
\hline \hline 2 theta $(\mathrm{Cu})$ & $(\mathrm{hkl})$ & Intensity \\
\hline 35.094 & $(100)$ & 25 \\
38.422 & $(002)$ & 30 \\
40.171 & $(101)$ & 100 \\
53.005 & $(102)$ & 13 \\
\hline \hline
\end{tabular}

TABLE IV. Indexed peaks of TiP. TiP-ICDD PDF 04-004-7240-Hexagonal $\left(\mathrm{P}_{3} / \mathrm{mmc}\right)$.

\begin{tabular}{lcc}
\hline \hline 2 theta $(\mathrm{Cu})$ & $(\mathrm{hkl})$ & Intensity \\
\hline 29.333 & $(100)$ & 12 \\
30.323 & $(101)$ & 18 \\
37.398 & $(103)$ & 100 \\
42.756 & $(104)$ & 28 \\
48.936 & $(105)$ & 21 \\
52.022 & $(110)$ & 44 \\
54.48 & $(112)$ & 0.3 \\
63.261 & $(008)$ & 8 \\
\hline \hline
\end{tabular}

TABLE V. Indexed peaks of $\mathrm{Ti}_{2} \mathrm{In}_{5} . \mathrm{Ti}_{2} \mathrm{In}_{5} \mathrm{ICDD}$ PDF 04-007-4080Tetragonal $(\mathrm{P} 4 / \mathrm{mbm})$.

\begin{tabular}{lcc}
\hline \hline 2 theta $(\mathrm{Cu})$ & $(\mathrm{hkl})$ & Intensity \\
\hline 25.159 & $(220)$ & 25 \\
28.187 & $(310)$ & 62 \\
29.78 & $(001)$ & 73 \\
32.238 & $(320)$ & 43 \\
34.864 & $(201)$ & 16 \\
35.879 & $(400)$ & 16 \\
36.037 & $(211)$ & 48 \\
37.023 & $(410)$ & 100 \\
38.138 & $(330)$ & 33 \\
\hline
\end{tabular}

TABLE V. (Continued.)

\begin{tabular}{lcc}
\hline \hline 2 theta $(\mathrm{Cu})$ & $(\mathrm{hkl})$ & Intensity \\
\hline 39.37 & $(221)$ & 22 \\
41.466 & $(311)$ & 77 \\
44.457 & $(321)$ & 44 \\
47.296 & $(401)$ & 17 \\
48.215 & $(411)$ & 27 \\
50.892 & $(421)$ & 16 \\
58.288 & $(620)$ & 8 \\
59.083 & $(540)$ & 5 \\
61.854 & $(002)$ & 13 \\
62.204 & $(630)$ & 11 \\
\hline \hline
\end{tabular}

${ }^{1}$ A. Katz, B. E. Weir, and W. C. Dautremont-Smith, J. Appl. Phys. 68, 1123 (1990).

${ }^{2}$ L. Persson, M. El Bouanani, M. Hult, H. J. Whitlow, M. Andersson, I. F. Bubb, P. N. Johnston, S. R. Walker, D. D. Cohen, N. Dytlewski, C. Zaring, and M. Östling, J. Appl. Phys. 80, 3346 (1996).

${ }^{3}$ M. B. Takeyama, A. Noya, T. Hashizume, and H. Hasegawa, in 10th International Conference on Indium Phosphide and Related Materials (1998), pp. 627-630.

${ }^{4}$ M. B. Takeyama, A. Noya, T. Hashizume, and H. Hasegawa, Jpn. J. Appl. Phys., Part 1 38, 1115 (1999).

${ }^{5}$ T. Kendelewicz, P. H. Mahowald, C. E. McCants, K. A. Bartness, I. Lindau, and W. E. Spicer, J. Vac. Sci. Technol., B 5, 1033 (1987).

${ }^{6}$ T. Chassé, W. G. Wilke, and K. Horn, Surf. Interface Anal. 14, 315 (1989). ${ }^{7}$ D. Wang and D. G. Ivey, Mater. Sci. Eng., B 41, 289 (1996).

${ }^{8}$ A. Appelbaum, M. Robbins, and F. Schrey, IEEE Trans. Electron Devices 34, 1026 (1987).

${ }^{9}$ N. S. Fatemi and V. G. Weizer, J. Appl. Phys. 73, 289 (1993).

${ }^{10}$ P. S. Mangat, P. Soukiassian, Y. Huttel, Z. Hurych, B. Gruzza, and A. Porte, Appl. Phys. Lett. 63, 1957 (1993).

${ }^{11}$ M. Ghaffour, A. Abdellaoui, M. Bouslama, A. Ouerdane, and B. Abidri, EPJ Web Conf. 29, 00020 (2012).

${ }^{12}$ P. Rodriguez, L. Toselli, E. Ghegin, M. Rebaud, N. Rochat, N. Chevalier, E. Martinez, and F. Nemouchi, ECS Trans. 69, 251 (2015).

${ }^{13}$ E. Ghegin, F. Nemouchi, J. Lábár, C. Perrin, K. Hoummada, S. Favier, S. Gurbán, and I. Sagnes, Microelectron. Eng. 156, 86 (2016).

${ }^{14}$ D. Cuypers, D. H. van Dorp, M. Tallarida, S. Brizzi, T. Conard, L. N. J. Rodriguez, M. Mees, S. Arnauts, D. Schmeisser, C. Adelmann, and S. De Gendt, ECS J. Solid State Sci. Technol. 3, N3016 (2014). 